\title{
Establishment of four new mesothelioma cell lines: characterization by ultrastructural and immunophenotypic analysis
}

\author{
A.M. Orengo*, L. Spoletini**, A. Procopio**, R.E. Favoni ${ }^{+}$, A. De Cupis ${ }^{+}$, A. Ardizzoni ${ }^{+}$, \\ B. Castagneto , M. Ribotta ${ }^{\#}$, P.G. Betta ${ }^{\#}$, S. Ferrini*, L. Mutti ${ }^{\S}$
}

\begin{abstract}
Establishment of four new mesothelioma cell lines: characterization by ultrastructural and immunophenotypic analysis. A.M. Orengo, L. Spoletini, A. Procopio, R.E. Favoni, A. De Cupis, A. Ardizzoni, B. Castagneto, M. Ribotta, P.G. Betta, S. Ferrini, L. Mutti. (C)ERS Journals Ltd 1999.

ABSTRACT: The aim of this study was to assess the biological characteristics of four new malignant mesothelioma (MM) cell lines. Since simian virus (SV)40 sequences have been recently detected in MM, SV40 large T antigen (Tag) expression was also analysed.

MM cell lines were characterized by morphological, ultrastructural and cytogenetic analysis. Expression of Tag and of relevant MM markers was studied by immunocytochemistry, surface antigens by indirect immunofluorescence and immunomodulating cytokines by enzyme-linked immunosorbent assay (ELISA).

The four MM cell lines, established from pleural effusions, showed a slow proliferation rate and pleomorphic changes during culture. Cell lines expressed vimentin, cytokeratins 8 and 18, and the mesothelial antigen recognized by HBME-1 monoclonal antibody, but not carcinoembryonic antigen. Surface human leukocyte antigen (HLA)-class I and intercellular adhesion molecule (ICAM)-1 molecules were present on all the cell lines. While HLA class II and CD86 were constitutively undetectable, HLA-class II was present after interferon (IFN)- $\gamma$ stimulation. All cell lines displayed abnormal karyotypes with chromosome 6 abnormalities. Transforming growth factor (TGF)- $\beta_{2}$ and interleukin (IL)-6 were constitutively secreted, while tumour necrosis factor (TNF)- $\alpha$ was secreted only in response to lipopolysaccharide. Intranuclear Tag was expressed in two cell lines.

The persistence of large $T$ antigen with human leukocyte antigen class $I$ and intercellular adhesion molecule-1 positivity may point to large $T$ antigen as a target for cytotoxic T-lymphocyte-based immunotherapy in some malignant mesothelioma patients.

Eur Respir J 1999; 13: 527-534.
\end{abstract}

\begin{abstract}
*Istituto Nazionale per la Ricerca sul Cancro, Centro di Biotechnologie Avanzate, Genoa, Italy. **Dept of Pathology, University of Chieti, Chieti, Italy. ${ }^{+}$Istituto Nazionale per la Ricerca sul Cancro, Genoa, Italy. "Hospital of Casale Monferrato, Casale Monferrato, Italy. " Dept of Pathology, Hospital of Alessandria, Italy. ${ }^{\S}$ Dept of Medicine, "S. Maugeri" Foundation, Institute for Research and Care, Italy.
\end{abstract}

Correspondence: L. Mutti

"S. Maugeri" Foundation

Via Gippa 3

13019 Varallo S (VC)

Italy

Fax: 390163203217

Keywords: Cell lines

mesothelioma

Received: April 141998

Accepted after revision November 81998

Partially financially supported by the "Italian League against Cancer" (Section of Alessandria).
Malignant mesothelioma (MM) is an aggressive cancer of the mesothelium, most often occurring in the pleural cavity and associated with previous exposure to asbestos fibres. Owing to the long latency period after exposure and the widespread use of asbestos fibres for many years, the incidence of MM is expected to rise until 2020 [1]. MM has been demonstrated to be resistant to any conventional therapy regimens including chemotherapy, radiotherapy and surgery, and the prognosis remains poor [2].

The discrepancy between the rising incidence of MM and the lack of success of new more effective therapeutic strategies may be related at least in part to inadequate knowledge of the biological properties of this rare tumour. It is hoped that a better understanding of MM biology may provide the rationale for new therapeutic strategies. In particular, improved knowledge of the modalities of MM development and progression, the genetic alterations, the phenotypic and antigenic profile, the identification of growth factors and cytokines secreted by MM and of their auto/paracrine loops, and finally, the sensitivity to antiproliferative drugs seem to be essential steps.

As far as tumour development and progression are concerned, recent data pointed to the presence of the oncogenetic simian virus (SV)40 genome and SV40 large $\mathrm{T}$ antigen (Tag) in MM specimens and to a possible role of SV40 as a cofactor in the development of MM [3, 4]. In addition, it was demonstrated that intrapleural injection of SV40 virus will induce MM in all hamsters injected [5].

The development of tumour cell lines has been an important tool in the setting up of suitable in vitro models for studying the biological properties of many tumours and to assess sensitivity to various drugs or biological response modifiers. However, as opposed to lung cancer, where many established cell lines are available, only a few MM cell lines have been established [6-8].

The aim of this study was the establishment of new MM cell lines and the assessment of some of the relevant biological characteristics such as: phenotypic and cytogenetic 
profile, ultrastructure, growth pattern and production of immunomodulatory cytokines. In addition, the possible presence of SV40 Tag in MM cell lines was investigated.

\section{Materials and methods}

\section{Study subjects and exposure history}

Pleural effusions were collected from patients with MM in order to generate short-term cultures of MM from 1989. Among them (approximately 20 cultures) four cultures were generated and owing to their long-lasting growth could be considered as established cell lines. The four patients from whom cell lines were derived were three males and one female ranging in age from 38-71 yrs at diagnosis.

All the patients were from the same area where residual environmental pollution from an asbestos factory that had been active for about $50 \mathrm{yrs}$ is still detectable (table 1). The persistent environmental pollution has been described as the cause of a higher mortality from MM among the inhabitants of the area regardless of occupational history [9].

All the patients were diagnosed using thoracoscopy and histological examination and were untreated. Three patients showed an epithelial histological subtype and one patient showed a mixed subtype.

\section{Generation of the short-term cell cultures}

Short-term cultures were generated by collecting pleural fluid via a sterile evacuative thoracentesis (for diagnostic purposes) and were centrifuged for $10 \mathrm{~min}$ at $150 \times g$; the final pellets were resuspended in a culture medium (M199; PBI International, Milan, Italy) containing 10\% heat-inactivated foetal calf serum (FCS), 1\% L-glutamine, penicillin $\left(0.1 \mathrm{mg} \cdot \mathrm{mL}^{-1}\right)$ and transferrin $80.5 \mu \mathrm{g} \cdot \mathrm{mL}^{-1}$ (Sigma, St Louis, MO, USA). The cells were plated in $75 \mathrm{~mL}$ culture flasks and left overnight at $37^{\circ} \mathrm{C}$ in a humidified atmosphere of $95 \%$ air and $5 \% \mathrm{CO}_{2}$.

The following day, the medium was replaced to remove nonadherent cells; thereafter the medium was replaced twice weekly and cells were passaged when they reached confluency in a monolayer (every 20-21 days).

Macrophages, red blood cells and lymphocytes were the main contaminants of the initial cultures but, since they do not replicate under the same conditions as MM, they were eliminated by cell passages. Normal mesothelial cells became senescent and failed to grow within two months.

\section{Generation of the established cell cultures}

Following the steps described above, the previous culture medium was replaced with Ham's-F10 medium (Biowhittaker, Verviers, Belgium) supplemented with $10 \%$ FCS, glutamine $(2 \mathrm{mM})$ and antibiotics $\left(0.02 \mathrm{IU} \cdot \mathrm{mL}^{-1}\right.$ penicillin and $0.02 \mathrm{mg} \cdot \mathrm{mL}^{-1}$ streptomycin) while the established cell line, MPP89, was maintained in Dulbecco's modified Eagle's medium (DMEM; Biowhittaker) with 5\% FCS, $1 \%$ nonessential amino acids and supplemented as above. Cell lines were considered as established after 30 passages and at least 11 months of culture. The cell lines were IST-Mes1, IST-Mes2, IST-Mes3 and MPP89 (table $1)$.

\section{Confirmation of the mesothelial origin of cell lines}

Morphological analysis. To confirm their mesothelial origin, MM cell lines were detached from culture flasks by gentle mechanical scraping or trypsinization. Cells were centrifuged at $350 \times g$ for $5 \mathrm{~min}$ and then analysed with standard morphological procedures using a light microscope and spray-fixed slides stored at room temperature.

Immunocytochemical studies. The specific staining for mesothelial origin was performed using the following antibodies: anti-cytokeratins 8 and 18 (clone CAM 5.2; Becton Dickinson, Milan, Italy) at a dilution of 1:40, anti-vimentin (clone V9; Dakopatts, Glostrup, Denmark) prediluted, anti-mesothelial cell (clone HBME-1, Dakopatts) at a dilution of 1:50, anti-carcinoembryonic antigen (CEA, Clone ZCEA; Zymed, CA, USA) at a 1: 3,000 dilution, and anti-calretinin (polyclonal antibody; Swant; Milan, Italy) at 1:8,000 dilution.

Immunostaining was performed using indirect streptavidin-biotin horseradish peroxidase (SAB/HRP) in an automated immunostainer (Dako TechMate ${ }^{\mathrm{TM}} 500$ ) with an incubation time of $30 \mathrm{~min}$ at room temperature for each primary antibody.

The entire cell population of the cultures were required to show an homogenous morphology corresponding to mesothelial origin and a phenotypic pattern of anti-cytokeratin, anti-vimentin, anti-HBME-1 and anti-calretinin positive with absence of staining for CEA, before being suitable for further study. To be defined positive for a monoclonal antibody (mAb), $\geq 95 \%$ of the cells of each cell line must have been stained, whereas for anti-calretinin $\geq 80 \%$ of the malignant cells (derived from epithelial histological subtype) must have been stained. Tag expression was evaluated by immunoperoxidase staining: the cell lines were fixed in acetone, washed with phosphatebuffered saline (PBS), air-dried and incubated with monoclonal Ab-1, specific for SV40 Tag (Oncogene Science, CA, USA) at a dilution of 1:40. The immunoperoxidase staining was performed using the Elite Vectasin $\mathrm{ABC}$ kit (Vector, IL, USA) according to the manufacturer's instructions. As a positive control, Tag expression was evaluated by the same method as in H9A cells (kindly provided by P. Rizzo and M. Carbone, Loyola University, Chicago, IL, USA). This cell line was derived from an SV40-induced mesothelioma in hamster. As a negative control the same methods were followed to stain established cell lines with monoclonal anti- $\beta$-galactosidase (Oncogene Science).

Table 1. - Characteristics of the cell lines and patients

\begin{tabular}{lcccc}
\hline & & \multicolumn{2}{c}{ Patients } \\
\cline { 4 - 5 } Cell line & Media & Histology & Sex & Age at diagnosis \\
\hline IST-Mes1 & Ham's-F10 & Epithelial & $\mathrm{F}$ & 70 \\
IST-Mes2 & Ham's-F10 & Epithelial & $\mathrm{M}$ & 71 \\
IST-Mes3 & Ham's-F10 & Mixed & $\mathrm{M}$ & 38 \\
MPP89 & DMEM & Epithelial & $\mathrm{M}$ & 67
\end{tabular}

M: male; F: female; DMEM: Dulbecco's modified Eagle's medium. 


\section{Cytogenetics and karyotyping}

The harvesting procedure consisted of in situ treatment with colcemid $0.1 \mu \mathrm{g} \cdot \mathrm{mL}^{-1}$ for $4-6 \mathrm{~h}$, hypotony in potassium chloride solution $\left(75 \mathrm{mosmol} \cdot \mathrm{L}^{-1}\right)$ for $10 \mathrm{~min}$ at room temperature and two 10 min fixations in methanolacetic acid (3:1).

Cells were heated for $2 \mathrm{~h}$ at $90^{\circ} \mathrm{C}$ and G-bands for chromosome analysis were obtained by staining in trypsingiemsa. At least 40 metaphases were analysed in 20 clones for each patient. Clonal chromosome abnormality was confirmed if present in $\geq 2$ clones ( 3 clones in case of losses). Chromosome identification and designation were in accordance with the International System for Human Cytogenetic Nomenclature (ISCN) [10].

\section{Ultrastructural analysis}

The cell cultures were washed with $0.1 \mathrm{M}$ PBS, then fixed for $3 \mathrm{~h}$ at $4{ }^{\circ} \mathrm{C}$ in $2.5 \%$ glutaraldehyde in PBS. The cultures were scraped and washed four times in $0.1 \mathrm{M}$ PBS. The samples were post-fixed with $1.33 \%$ osmium tetroxide in PBS for an additional $1 \mathrm{~h}$ at $4^{\circ} \mathrm{C}$, dehydrated in a graded series of ethanol solutions, embedded in Epon 812 (Rome, Italy), stained with uranyl acetate and lead citrate and examined under a Philips 201 transmission electron microscope (Milan, Italy).

\section{Cell growth studies}

Single-cell suspension cultures of log-phase growing cells were plated in triplicate in Petri dishes $35 \mathrm{~mm}$ diameter) at a density of $5 \times 10^{3}-20 \times 10^{3}$ cells in $2 \mathrm{~mL}$ of the appropriate culture medium and allowed to attach overnight at $37^{\circ} \mathrm{C}$ and $5 \% \mathrm{CO}_{2}$. The next day, and at days 2, 3, 4, 5, 7, 9 and 11 after plating, a monolayer from each well was harvested by trypsinization. Cells were counted in a haemocytometer chamber and the viability was evaluated by the trypan blue dye exclusion test. Doubling-time for each well was then derived from the exponential growth phase using the formula

$$
\mathrm{V}=\mathrm{V}_{0} \times 2 \mathrm{n}
$$

where $V=$ the final cell number, $V_{0}=$ the starting cell number and $n=$ the number of hours in culture.

\section{Phenotypic analysis by cytofluorometry}

Cytofluorometric analysis (fluorescence-activated cell sorting, FACScan; Becton Dickinson) of the four established cell lines was carried out by direct staining with phycoerythrin (PE)-labelled anti-LeuM6 (CD1a, Clone Vit 6b; Bender Medsystems, Vienna, Austria) and fluoroscein isothiocyanate (FITC)-labelled anti-LeuM3 (CD14, Clone Tuk-4, Bender Medsystems). For the following antigens, indirect immunofluorescence was used: human leukocyte (HLA)-class I (W6.32 mAb American Type Culture Collection, Rockville, MD, USA), HLA class II (D1.12mab, kindly provided by R.S. Accolla, University of Varese, Varese, Italy), B7.2 (CD86; Ancell, Bayport, MN, USA), and intercellular adhesion molecule (ICAM)-1 (CD54;
Bender MedSystems). A FITC goat anti-mouse immunoglobulin (Southern Biotec, Birmingham, AL, USA) was used as the second-step reagent. Negative control cells were stained with secondary reagent only. Stained cells were resuspended in $200 \mathrm{~mL}$ medium and analysed in a FACScan cytofluorometer.

Immunostaining results are expressed as mean fluorescence intensity (MFI) and as percentage of positive cells. FACScan analysis was performed in resting state or after preactivation with $100 \mathrm{U} \cdot \mathrm{mL}^{-1}$ human interferon (IFN)- $\gamma$ for 2 days.

\section{Immunomodulatory cytokine production}

Cytokine assays were performed in culture supernatants from flasks in which cells were confluent. The levels of tumor necrosis factor (TNF)- $\alpha$, interleukin (IL)- 6 and transforming growth factor (TGF)- $\beta_{2}$ were determined by enzyme immunoassay (EIA) using commercially available kits according to the instructions provided by the manufacturer (TNF- $\alpha$ EIA, Medgenix Diagnostics, Belgium; IL-6 EIA; Medgenix Diagnostics; TGF- $\beta_{2}$; R\&D Systems, MN, USA). The TNF- $\alpha$ assay was performed before and after stimulation with lipopolysaccharide (LPS) at 1 $\mu \mathrm{g} \cdot \mathrm{mL}^{-1}$ in the supernatant of confluent cells. Values are expressed as mean of three measurements.

\section{Results}

\section{Establishment of four novel mesothelioma cell lines}

The four cell lines, IST-Mes1, IST-Mes2, MPP89 and IST-Mes3 were successfully established from four out of 20 samples of mononuclear cells isolated from pleural effusions of patients with MM (table 1). These cell lines could be subcultured for $>50$ times and could be regrown in culture after cryopreservation at different culture stages.

While primary cell cultures maintained a spindle-like morphology during the first passages, all the established cell lines showed pleomorphic shapes with significant changes in relationship to the stage of the cultures. For 24 $48 \mathrm{~h}$ after detachment and subculturing, the cells were mainly spindle-shaped. Later cultures displayed a progressive clustering with a tendency towards tubular structures and a more epithelial-like morphology with the presence of cytoplasmic protrusions similar to pseudopodia. At confluence, the cultures appeared as a monolayer of flat cells with few cytoplasmic protrusions. This peculiar growth pattern was more evident in IST-Mes1 and IST-Mes2, while IST-Mes-3 and MPP89 tended to maintain a spindlelike morphology.

In general, MM cell lines showed a relatively slow growth rate. Figure 1 reports the growth rate characteristics of the four cell lines.

Confirmation of the mesothelial origin and immunophenotypic analysis of malignant mesothelioma cell lines

Immunohistochemical analysis on fixed cells showed a positive reaction for anti-cytokeratins, anti-vimentin mAbs and for the anti-mesothelial HBME-1 mAb [11], with a 


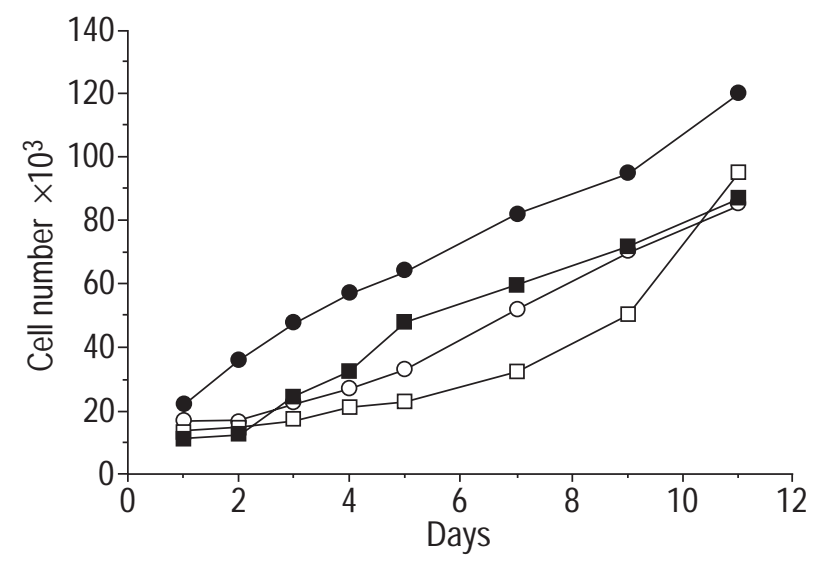

Fig. 1. - Cell growth studies of mesothelioma cell lines. Doubling-time for each cell line is shown. Data points represent the mean of three independent experiments performed in triplicate. $\bigcirc$ : IST-Mes1; ๑: ISTMes2; $\square$ : IST-Mes3; $\mathbf{0}$ : MPP89.

cytoplasmic pattern for anti-cytokeratin 8 and 18 , a predominantly cytoplasmic pattern for vimentin and a membrane pattern of expression for the mesothelial antigen HBME-1. No detectable positive reaction for CEA antigen and for anti-LeuM1, anti-LeuM3 and anti-LeuM6 was observed in any of the cell lines (table 2). In addition, an anti-calretinin $\mathrm{mAb}$ displayed a cytoplasmic pattern of reactivity in approximately $80 \%$ of cells from the four cell lines (data not shown). HLA class I and CD54 were consistently expressed on all four tumour cells while HLA class II and CD86 were negative by immunofluorescence and cytofluorometric analysis. Low levels of HLA class II and an enhanced expression of HLA class I and CD54 but no significant change in CD86 were observed upon treatment with IFN- $\gamma$.

\section{Ultrastructural analysis}

Ultrastructural analysis of IST-Mes1, IST-Mes2 and MPP89 cell lines showed epithelioid elements with a convoluted nucleus, finely dispersed chromatin and evident nucleoli. Abundant cytoplasm containing mitochondria, rough endoplasmic reticulum and the occasional Golgi complex were observed. Glycogen granules were also observed (fig. 2a) along with perinuclear intermediate filaments (fig. 2b). The cell surface was rich in microvilli without a cytoskeletal axis, with a length-diameter ratio $>10$. In addition, desmosomes were observed in the cellular aggregates. Ultrastructural observation of the cell line IST-Mes3 showed spindle-shaped elements with rare surface microvilli. Perinuclear intermediate filaments were seen in addition to numerous mitochondria, abundant rough endoplasmic reticulum and glycogen granules. These elements demonstrate a mesothelial origin with sarcomatous morphology (fig. 2c).

\section{Cytogenetic analysis}

All the cell lines exhibited abnormal karyotypes with both numeric and structural chromosomal abnormalities. IST-Mes2 was hypodiploid, while IST-Mes3 and MPP89 were hyperdiploid and IST-Mes1 was hypohyperdiploid. Monosomy 17 was found in all the cell lines whilst in the MPP89 cell line both chromosomes 17 were absent. Monosomy 13 was found in three cell lines, monosomy 22 in two cell lines. The most frequent structural changes were represented by deletion and/or translocations of chromosome 6 (all four cell lines), chromosome 1 and chromosome 3 (both on three cell lines). Isochromosome 6 was also found in one cell line and this abnormality coexisted with other structural changes.

\section{Immunomodulatory cytokine production}

As shown in table 3, all the four cell lines were capable of releasing a constitutively high amount of IL-6 (>1,100 $\mathrm{pg} \cdot \mathrm{mL}$ supernatant ${ }^{-1}$ of confluent cultures) and variable levels of TGF- $\beta_{2}$ (range 234-4,711 pg.mL supernatant ${ }^{-1}$ of confluent cultures).

No spontaneous TNF- $\alpha$ secretion was detectable in the supernatant of cell lines. However, after stimulation with LPS all four MM cell lines were shown to possess the capability to release substantial amounts of TNF- $\alpha(>150$ $\mathrm{pg} \cdot \mathrm{mL}$ supernatant ${ }^{-1}$ of confluent cultures).

\section{Large T antigen protein expression}

In two out of four MM cell lines the Tag protein was detectable (IST-Mes1 and IST-Mes2). Approximately 95\% of IST-Mes 1 and $80 \%$ of IST-Mes 2 cells were positive for intranuclear Tag protein (fig. 3a). Tag protein was undetectable in the remaining two cell lines. Positive intranuclear staining was revealed in $90 \%$ of H9A cells (fig. $3 b)$ while anti- $\beta$-galactosidase $\mathrm{mAb}$ did not stain the established cell lines (fig. 3c) nor H9A cells (data not shown). No relationship between Tag protein expression and the other features of MM cell lines was found.

\section{Discussion}

This study reported on the establishment of four human MM cell lines that retained phenotypic and ultrastructural

Table 2. - Immunohistochemical analysis of cell lines

\begin{tabular}{lcccccc}
\hline Cell line & CAM 5.2 & HBME-1 & Z-CEA & LeuM1 & Calretinin & LeuM6 \\
\hline IST-Mes1 & + & + & + & - & - & - \\
IST-Mes2 & + & + & - & - & + & - \\
IST-Mes3 & + & + & - & - & - & - \\
MPP89 & + & - & - & - \\
\hline
\end{tabular}

Positive cell lines $(+)$ : staining of $\geq 95 \%$ of the cells; negative cell line (-): staining of $<5 \%$ of the cells; anti-calretinin monoclonal antibody stained $80 \%$ of the epithelial cell component. CEA: carcinoembrionic antigen. 

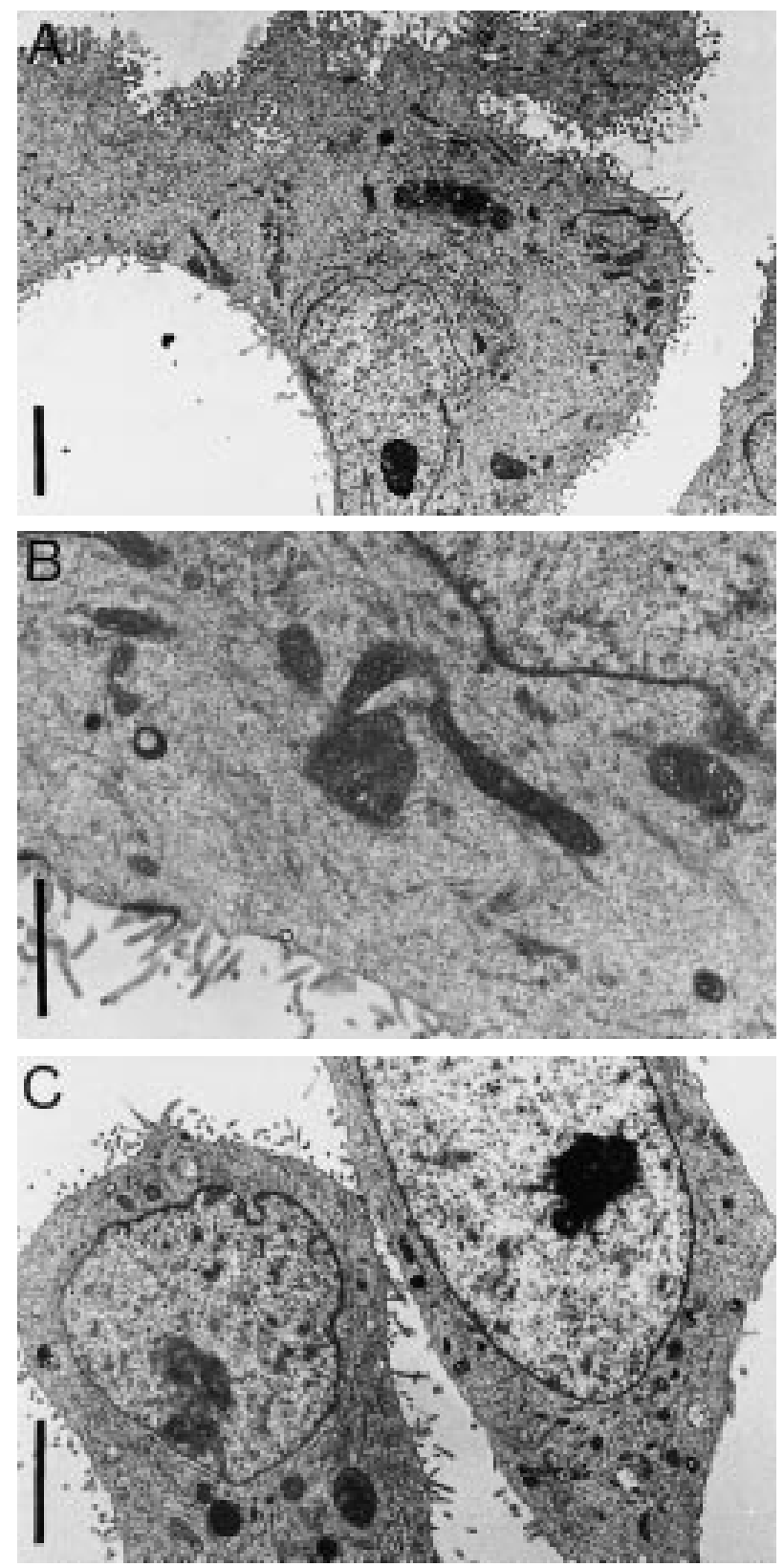

Fig. 2. - Ultrastructural analysis of cell lines. a) IST-Mes1 cell line shows cytoplasmic glycogen granules. Internal scale bar $1.1 \mu \mathrm{m}$. b) Ultrastructural detail showing long microvilli and perinuclear tonofilaments of the IST-Mes1 cell line. Internal scale bar $=500 \mathrm{~nm}$. c) ISTMes 3 cell line with spindle-shaped pattern. Internal scale bar $=1 \mu \mathrm{m}$.

features typical of MM cells, including the presence of surface molecules involved in the immune response and a highly abnormal karyotype with the common hallmark of chromosome 6 abnormalities. An interesting biological characteristic of these $\mathrm{MM}$ cell lines was the constitutive secretion of IL- 6 and TGF- $\beta_{2}$ and the ability to respond to LPS stimulation by releasing TNF- $\alpha$. In addition, as a marker of SV40 infection, two out of four cell lines had demonstrable intranuclear Tag.

An important objective in the cytogenetic study of MM has been the identification of common specific chromosomal changes in these neoplastic cells involving onco-
Table 3. - Releasing properties of cell lines

\begin{tabular}{lcccr}
\hline Cell line & IL-6 & $\begin{array}{c}\text { TNF- } \alpha \\
\text { (Spont) }\end{array}$ & $\begin{array}{c}\text { TNF- } \alpha \\
\text { (after LPS) }\end{array}$ & TGF- $\beta_{2}$ \\
\hline IST-Mes1 & 1198 & ND & 155 & 234 \\
IST-Mes2 & 1471 & ND & 201 & 530 \\
IST-Mes3 & 2123 & ND & 189 & 3744 \\
MPP89 & 1234 & ND & 306 & 4711 \\
\hline
\end{tabular}

Values are expressed in $\mathrm{pg} \cdot \mathrm{mL}^{-1}$ as mean of three measurements. IL-6 interleukin-6; TNF- $\alpha$ : tumour necrosis factor- $\alpha$; TGF- $\beta_{2}$ : transforming growth factor- $\beta_{2}$; LPS: lipopolysaccharide (1 $\mathrm{mg} \cdot \mathrm{mL}$ supernatant ${ }^{-1}$ of confluent cultures); ND: not detectable.

genes or tumour suppressor genes (TSG) which may have a pathogenetic role [12]. The finding of highly abnormal karyotypes in all four cell lines allowed us to look for cytogenetic alterations common to all MM cells. Thus, in all the four cell lines studied, monosomy 17 and structural deletion of $6 \mathrm{q}$ were detected.

Concerning the relevance of monosomy 17, the p53 gene is located on this chromosome. However, p53 has been reported to be normally expressed and no structural alterations of this gene have been reported in MM [13]. Nevertheless, a functional inactivation of a wild type p53 may occurr in MM due to binding to SV40 Tag protein [4]. In the present cell lines, monosomy 17 was detected within a relatively highly altered karyotype suggesting a secondary abnormality owing to an aspecific chromosomal instability.

Deletions of $6 \mathrm{q}$ have been reported in other studies performed on tumour specimens from patients [14] and the role of a putative TSG located on this chromosome has been suggested as being an early oncogenic change for the onset of MM [15]. More recently, a study using microsatellite analysis on MM suggested the presence of multiple TSGs on chromosome 6q [16]. In addition, a variety of other solid tumours have revealed chromosome $6 \mathrm{q}$ abnormalities $[17,18]$ and the tumorigenicity of melanoma cells, in which chromosome $6 \mathrm{q}$ abnormalities are frequently described [19] was shown to be controlled by the introduction of human chromosome 6 [20], whereas SV40induced immortalization of human fibroblasts was shown to be linked to loss of heterozygosity of chromosome 6q26-27 [21]. Finally, a pro-apoptotic gene has been identified on 6 q27 [22]. Further studies will be required to assess the pathogenetic role of alterations of putative TSG on chromosome $6 \mathrm{q}$ in the oncogenic process of MM and the current cell lines may represent a useful tool for investigating this issue.

Although exposure to asbestos fibres is the most important pathogenetic factor of MM, the presence of SV40 has been proposed as an additional pathogenetic factor or cofactor for MM. Thus, SV40 positivity has been detected in a substantial fraction of MM specimens [23] and the capability of Tag to interact with oncosuppressive proteins $\mathrm{Rb}$ and $\mathrm{p} 53$ has been demonstrated in MM [3, 4]. It is known that in mesothelial cells the physical interaction between Tag and oncosuppressive proteins results in derangement of the cell cycle [24]. Therefore the data indicating that Tag protein expression persists in a fraction $(50 \%)$ of mesothelioma cell lines may add further suggestive evidence for a role of SV40 in MM, providing an important tool for the assessment of SV40-related 

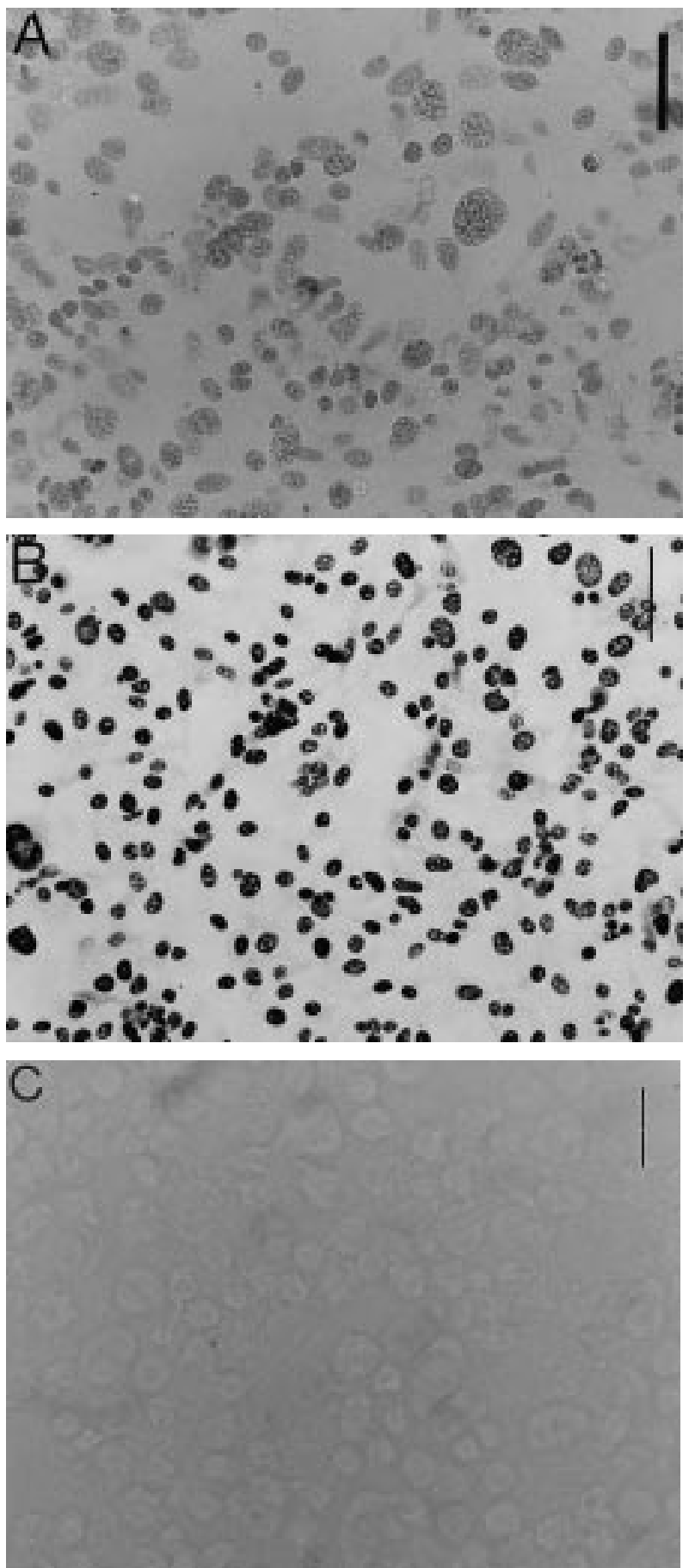

Fig. 3. - Tag protein expression. IST-Mes1, IST-Mes2 and H9A cell lines all showed intranuclear staining. a) Intranuclear staining of the ISTMes 1 cell line (95\% of cells stained). b) Positive control: intranuclear staining of the H9A cell line ( $90 \%$ of cells stained) (original magnification $\times 40$ ). c) Negative control: anti- $\beta$-galactosidase monoclonal antibody did not produce any staining of the IST-Mes1 cell line. Internal scale bar $=10 \mu \mathrm{m}$.

functional effects on these neoplastic cells. Furthermore, the high percentage of Tag-positive cells referred to above (higher than previously shown) [23] and the prolonged persistence of this nuclear phosphoprotein points to a potential role of Tag as a target molecule for inducing an immune response against MM cells. In this context, using murine models, vaccination against Tag was shown to confer protection against a lethal challenge with SV40transformed cells [25].

A prior study showed how primary MM cultures can present recall antigens to autologous CD4 lymphocytes through a major histocompatability complex (MHC)-mediated process [26]. On the contrary, the present data on the immunophenotypic analysis show that such Tag-positive MM established cells display surface expression of only ICAM-1 and MHC-I molecules. Since these molecules are required for adhesion and presentation of viral antigenic peptides to cytotoxic T-lymphocyte (CTL) effector cells, the present cell lines are a suitable candidate to directly assess MM cell sensitivity to Tag-specific CTL MHC-Irestricted lysis.

This is a critical issue in establishing the possible effectivness of CTL-based immunotherapy strategies for MM. However, the absence of MHC-II, which may be expressed at low levels only following incubation with IFN- $\gamma$, and the persistent lack of the B7 costimulatory molecules (even after stimulation with IFN- $\gamma$ ) indicate that the established MM cells per se are ineffective in initiating a MHC-II-restricted T-helper response.

Previous observations that several factors produced by MM cells may inhibit the immune response were suggested by the finding that the introduction by gene transfer of IL-2, allogenic MHC-I or B71 protein alleles into murine cells did not result in the induction of an effective immune responses [27, 28].

TGF- $\beta_{2}$ factors are produced by several human cancers and are involved in several functions such as the regulation of cell growth, fibrosis, angiogenesis and also immunosuppression [29]. TGF- $\beta_{2}$ has been found in the pleural fluid of MM and expression of messenger ribonucleic acid (mRNA) and protein has been detected in some murine and human MM cell lines [27]. In murine MM models, antisense TGF- $\beta_{2}$ has been demonstrated to increase lymphocyte activity, number of tumour infiltrating lymphocytes and to inhibit MM cell growth [30] and this cytokine was revealed to negatively affect macrophagic antigen presenting capability [31] and CD3 subunit expression and cytokine release during MM development [32].

Although IL-6 is considered mainly as a pro-inflammatory cytokine, high levels of this cytokine have been associated with tumour progression in humans [33] including MM where intrapleural IL-6 levels could be used in monitoring the response to therapy [34] and are significantly higher than in patients with adenocarcinoma [35]. IL-6 serum levels and the release of IL- 6 by MM cells was respectively shown to be related to increased platelet counts [35] and were suspected to be related with the cachexia often present in these patients [31].

The immunomodulatory effects of IL-6 are well known. Blockade of IL-6 by specific antibodies in murine MM models inhibited cachexia and increased tumour infiltrating macrophages and lymphocytes [36]. Mice challenged intraperitoneally with IL-6-producing MM cells demonstrated a progressive thymic atrophy and downregulation of all lymphocyte markers [31].

The availability of MM cell lines has allowed the direct assessment that immunodepressant factors are actually produced by tumour cells rather than reactive cell elements, providing evidence for the secretion of relevant amounts of TGF- $\beta_{2}$ and IL- 6 directly by human MM cells, further 
stressing the possibility of a pathogenetic role of these cytokines as auto/paracrine tumour factors in $\mathrm{MM}$ and in the down-regulation of the immune response.

Like IL- 6 , high levels of TNF- $\alpha$ have been found in MM pleural effusion (E. Gati, unpublished data) and a role in determining cachexia, fever and impaired immune response in patients with MM has been described [31] even though TNF- $\alpha$ has been directly found to inhibit the growth of MM cells [37]. However, the absence of spontaneous release of TNF- $\alpha$ may suggest that detection in the pleural fluid of patients depends on the inflammatory reaction rather than the direct release by neoplastic cells. Despite this finding, the TNF- $\alpha$-releasing capability by MM following LPS stimulation does not rule out a role for the MM cell itself in TNF- $\alpha$ production in patients, possibly in response to unknown stimuli, suggesting a potential direct role of the biological activity of tumour mass in inducing cachexia in these patients.

In conclusion, the characterization of four novel malignant mesothelioma cell lines with chromosome 6 alterations and, in two cases, $\mathrm{T}$ antigen protein expression, provides further evidence for the possible pathogenetic role of these factors in malignant mesothelioma. In addition, the expression of large T antigen protein, major histocompatability molecule class I and intracellular adhesion molecule-1 suggests the possibility of cytotoxic T-lymphocyte-based immunotherapy strategies for this tumour, although the release of immunosuppressive cytokines by malignant mesothelioma cells may be a limiting factor. In the light of these findings, the effects of transfection of other molecules required in the immune response (e.g. B7 family proteins), blocking immunodepressant factors (transforming growth factor- $\beta_{2}$ and interleukin-6) or other factors also involved in paraneoplastic symptoms (e.g. tumour necrosis factor- $\alpha$ ) should be studied to plan new therapeutic immunotherapies. The above cell lines may help in further investigating these issues.

\section{References}

1. Peto J, Hodgson JT, Matthews FE, Jones JR. Continuing increase in mesothelioma mortality in Britain. Lancet 1995; 345: 535-539.

2. Sugarbaker DJ, Norberto J. Multimodality management of malignant pleural mesothelioma. Chest 1998; 113: $61 \mathrm{~s}-65 \mathrm{~s}$.

3. De Luca A, Baldi A, Esposito V, et al. The retinoblastoma gene family $\mathrm{pRb} / \mathrm{p} 105, \mathrm{p} 107, \mathrm{pRb} 2 / \mathrm{p} 130$ and simian virus-40 large T-antigen in human mesothelioma. Nature Med 1997; 8: 913-916.

4. Carbone M, Rizzo P, Grimley PM, et al. Simian Virus-40 large $\mathrm{T}$ antigen binds $\mathrm{p} 53$ in human mesotheliomas. Nature Med 1997; 8: 908-912.

5. Cicala C, Pompetti F, Carbone M. SV40 induces mesothelioma in hamsters. Am J Pathol 1993; 142: 15241533.

6. Versnel MA, Bouts MJ, Hoogsteden HC, van der Kwast TH, Delahaye M, Hagemeijer A. Establishment of human malignant mesothelioma cell lines. Int J Cancer 1989; 44: 256-260.

7. Mannings LS, Whithaker D, Murch AR, et al. Establishment and characterization of five human malignant mesothelioma cell lines derived from pleural effusions. Int J Cancer 1991; 47: 285-290.
8. Pass HI, Stevens EJ, Oie H, et al. Characteristics of nine newly derived mesothelioma cell lines. Ann Thorac Surg 1995; 59: 835-844.

9. Magnani C, Terracini B, Ivaldi C, Botta M, Mancini A, Andrion A. Pleural malignant mesothelioma and nonoccupational exposure to asbestos in Casale Monferrato, Italy. Occup Environ Med 1995; 52: 362-367.

10. An International System for Human Cytogenetic Nomenclature. Mitelman F, ed. Basel, Karger, 1995.

11. Donna A, Betta PG, Chiodera P, et al. Newly marketed tissue marker for malignant mesothelioma. Immunoreactivity of rabbit AMAD-2 antiserum compared with monoclonal antibody HBME-1 and a review of the literature on so called antimesothelioma antibodies. Hum Pathol 1997; 28: 993-995.

12. Knuutila S, Tiainen M, Tammilheto L, Rautonen L, Pyrhonen S, Mattson K. Cytogenetics of human malignant mesothelioma. Eur Respir Rev 1993; 3: 25-28.

13. Mor O, Yaron P, Huszar M, et al. Absence of p53 mutations in malignant mesotheliomas. Am J Respir Cell Mol Biol 1997; 16: 9-13.

14. Bjorkqwist AM, Tammilehto L, Antilla S, Mattson K, Knuutila S. Recurrent DNA copy number changes in 1q, $4 q, 6 q, 9 p, 13 q, 14 q$ and $22 q$ detected by comparative genomic hybridization in malignant mesothelioma. $\mathrm{Br} J$ Cancer 1997; 75: 523-527.

15. Meloni AM, Stephenson CF, Li FP, Sandberg AA. Del (6q) as a possible primary change in malignant mesothelioma. Cancer Genet Cytogenetic 1992; 59: $57-$ 61.

16. Bell DW, Jhanwar SC, Testa JR. Multiple regions of allelic loss from chromosome arm $6 \mathrm{q}$ in malignant mesothelioma. Cancer Res 1997; 57: 4057-4062.

17. Cooke IE, Shelling AN, Le Meuth VG, Charnock FML, Ganesan TS. Allele loss on chromosome arm 6q and fine mapping of the region at $6 \mathrm{q} 27$ in epithelial ovarian cancer. Genes Chrom Cancer 1996; 15: 223-233.

18. Menasce LP, Orphanos V, Santibanez-Koref M, Boyle JM, Harrison CJ. Common region of deletion on the long arm of chromosome 6 in Non-Hodgkin's lymphoma and acute lymphoblastic leukaemia. Genes Chrom Cancer 1994; 10: 286-288.

19. Millikin D, Meese E, Vogelstein B, Witkowski C, Trent J. Loss of heterozygosity for loci on the long arm of chromosome 6 in human malignant melanoma. Cancer Res 1991; 51: 5449-5553.

20. Trent J, Stanbridge E, McBride HL, et al. Tumorigenicity in human melanoma cell lines controlled by introduction of human chromosome 6. Science 1990; 247: 568-571.

21. Banga SS, Kim S, Hubbard K, et al. SEN6, a locus for SV40-mediated immortalization of human cells, maps to 6q26-27. Oncogene 1997; 14: 313-321.

22. Kawakami T, Furukawa Y, Sudo K, et al. Isolation and mapping of a human gene (PDCD2) that is highly homologous to Rp8, a rat gene associated with programmed cell death. Cytogenet Cell Genet 1995; 71: 41-43.

23. Carbone M, Pass HI, Rizzo P, et al. SV40 virus-like DNA sequences in human pleural mesothelioma. Oncogene 1994; 9: 1781-1790.

24. Levresse V, Moritz S, Renier A, et al. Effects of simian virus large $\mathrm{T}$ antigen expression on cell cycle control and apoptosis in rat pleural mesothelial cells exposed to DNA damaging agents. Oncogene 1998; 16: 1041-1053.

25. Bright RK, Shearer MH, Kennedy RC. Immunization of $\mathrm{BALB} / \mathrm{c}$ mice with recombinant simian virus 40 large tumor antigen induces antibody-dependent cell mediated 
cytotoxicity against simian virus transformed cells: an antibody based mechanism for tumor immunity. $J$ Immunol 1994; 153: 2064-2071.

26. Mutti L, Valle MT, Balbi B, et al. Primary human mesothelioma cells express class II MHC, ICAM1, and B72 and can present recall antigens to autologous blood lymphocytes. Int J Cancer 1998; 78: 740-749.

27. Garlepp MJ, Leong CG. Biological and immunological aspects of malignant mesothelioma. Eur Respir J 1995; 8: 643-650.

28. Leong CC, Marley JV, Loh S, Robinson BW, Garlepp MJ. The induction of immune response to murine malignant mesothelioma by IL2 gene transfer. Immunol Cell Biol 1997; 75: 356-359.

29. Ruscetti FW, Palladino MA. Transforming growth factorbeta and the immune system. Prog Growth Factor Res 1991; 3: 159-171.

30. Marzo AL, Fitzpatrick DR, Robinson BW, Scott B. Antisense oligonucleotides specific for tranforming growth factor $\beta_{2}$ inhibit the growth of malignant mesothelioma both in vitro and in vivo. Cancer Res 1997; 57: 32003207.

31. Bielefeldt-Ohmann H, Fitzpatrick DR, Marzo AL, et al. Patho- and immunobiology of malignant mesothelioma: characterization of tumor infiltrating leukocytes and cyto- kine production in a murine model. Cancer Immunol Immunother 1994; 39: 347-359.

32. Jarnicki AG, Fitzpatrick DR, Robinson BW, BielefeldtOhmann H. Altered CD3 chain and cytokines gene expression in tumor infiltrating T-lymphocytes during the development of mesothelioma. Cancer Lett 1996; 103: 1-9.

33. Blay JY, Negrier S, Combaret V, et al. Serum levels of interleukin 6 as a prognosis factor in metastatic renal carcinoma. Cancer Res 1992; 52: 3317-3322.

34. Zeng L, Buard A, Monnet I, Jaurand MC. In vitro effects of recombinant human interferon gamma on human mesotheliolma cell lines. Int J Cancer 1993; 55: 515-520.

35. Nakano T, Chaininan AP, Shinjo M, et al. Interleukin 6 and its relationship to clinical parameters in patients with malignant pleural mesothelioma. Br J Cancer 1998; 77: 907-912.

36. Bielefeldt-Ohmann H, Marzo A, Himbeck RP, Jarnicki $\mathrm{AG}$, Robinson BW, Fitzpatrick DR. Interleukin 6 involvement in mesothelioma pathobiology: inhibition by interferon alpha immunotherapy. Cancer Immunol Immunother 1995; 40: 241-250.

37. Bowman RV, Manning LS, Davis MR, Robinson BW. Chemosensitivity and cytokine sensitivity of malignant mesothelioma. Cancer Chemother Pharmacol 1991; 28: $420-426$. 